\title{
A case of eosinophilic granulomatosis with polyangiitis presented with blisters on the tongue
}

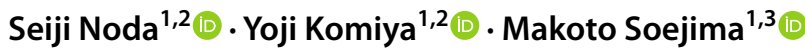

Received: 27 January 2022 / Revised: 23 February 2022 / Accepted: 28 February 2022 / Published online: 5 March 2022

(c) The Author(s), under exclusive licence to International League of Associations for Rheumatology (ILAR) 2022

\section{Presentation}

A 47-year-old female with a 7-year history of asthma was admitted for paresthesia on the lower limbs, along with purpura and painful blisters on the scalp, ears, lower limbs, and tongue (Fig. 1A). Paresthesia and hyperalgesia were observed on the lower-distal limbs. Manual muscle test score was 4 out of 5 . Peripheral severe eosinophilia $(2,869 / \mu \mathrm{L})$, C-reactive protein $(12.12 \mathrm{mg} / \mathrm{dL}$, normal range: $<0.3 \mathrm{mg} /$ $\mathrm{dL}$ ), and anti-myeloperoxidase anti-neutrophil cytoplasmic antibody (100 IU/mL) were observed. A computed tomography scan showed consolidations with pleural effusion in both lungs. Skin biopsy revealed infiltration of polynuclear cells and necrotizing vasculitis with fibrinoid deposits. Her condition was diagnosed as eosinophilic granulomatosis with polyangiitis (EGPA) involving lung and sensory nerve without motor nerve. We administered $1 \mathrm{mg} / \mathrm{kg} /$ day of prednisolone following $1,000 \mathrm{mg} /$ day of methylprednisolone for 3 days. At day 14 after the treatment, we added $750 \mathrm{mg}$ of cyclophosphamide. Peripheral eosinophilia did not improve despite the initial treatment, and drop foot appeared on the left side at day 25 . We prioritized treatment over electromyoneurography since neuropathy progressed rapidly. Intravenous immunoglobulin was started at day 25 for 5 days. We administrated rituximab (RTX) to treat peripheral motor neuropathy at day 31 . RTX improved skin and tongue lesions (Fig. 1B) as well as motor neuropathy and peripheral eosinophilia at day 40 .

\section{Discussion}

EGPA is a rare disease with 1.22 cases per million personyear (incidence) and 15.27 cases per million individuals (prevalence) [1]. Blister lesions are observed as cutaneous lesions in $10.2 \%$ of EGPA patients [2]. Concerning oral lesions in EGPA, only ulcers have been previously reported [3-5]. Our patient had blisters on the tongue, which are uncommon in EGPA as both oral and cutaneous manifestations. Less common lesion such as blisters on the tongue might be very important for both early diagnosis and treatment in a patient with EGPA.
Seiji Noda

noda.rheu@tmd.ac.jp

Yoji Komiya

komiya.rheu@tmd.ac.jp

Makoto Soejima

soejima.rheu@tmd.ac.jp

1 Department of Rheumatology, Ome Municipal General Hospital, Ome, Japan

2 Department of Rheumatology, Graduate School of Medical and Dental Sciences, Tokyo Medical and Dental University (TMDU), 1-5-45, Yushima, Bunkyo-ku, Tokyo 113-8519, Japan

3 Department of Rheumatology, Soka Municipal Hospital, Soka, Japan 
Fig. 1 The painful blisters on the tongue. A Before treatment, the patient presented blisters on the surface of the tongue. B After treatment with prednisolone and rituximab, blisters disappeared

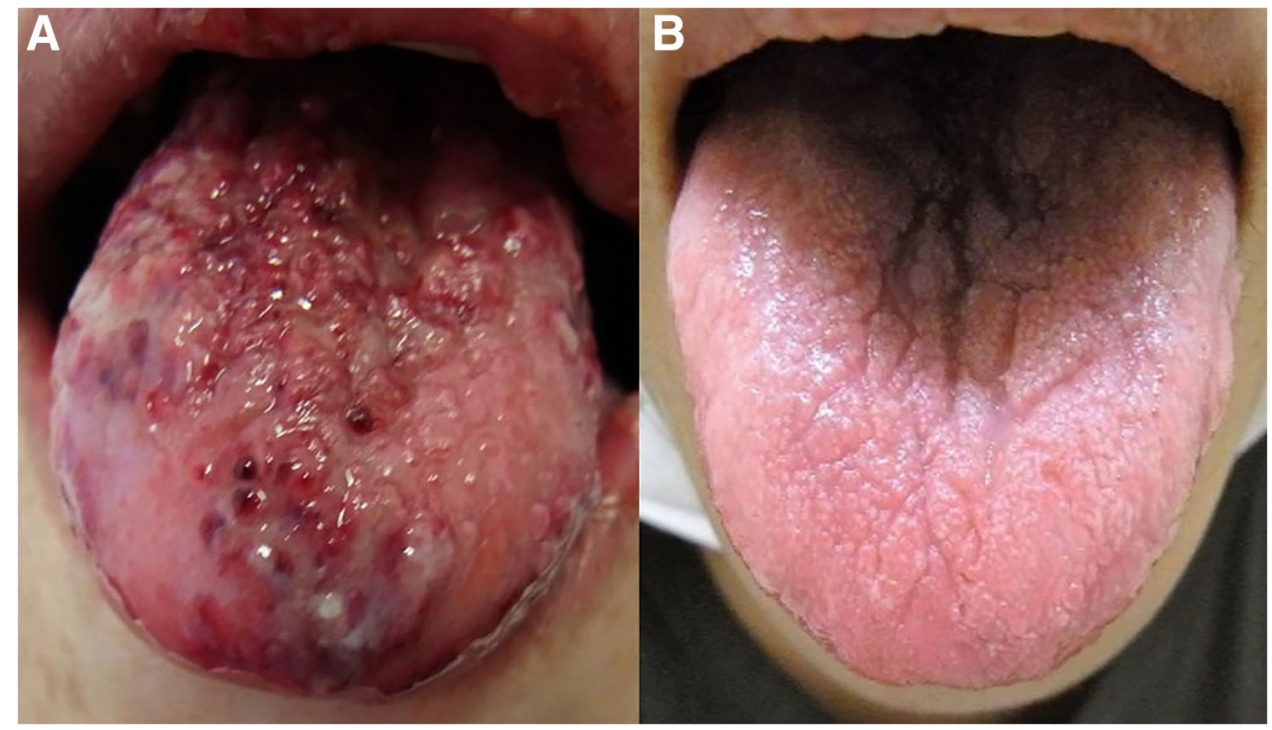

Acknowledgements We would like to thank Editage (www.editage. com) for English language editing.

Author contribution All of the authors contributed to taking care of this patient, analyzed and interpreted data. SN and YK drafted the manuscript. MS supervised the manuscript. The final manuscript has been read and approved by all the authors for publication.

\section{Declarations}

Ethics approval and consent to participate Written informed consent for publication was obtained from the patient. We have approval from the medical research ethics committee of Ome Municipal General Hospital, where the patient was on follow-up (approval number: 2021011).

Disclosures None.

\section{References}

1. Jakes RW, Kwon N, Nordstrom B, Goulding R, Fahrbach K, Tarpey J et al (2021) Burden of illness associated with eosinophilic granulomatosis with polyangiitis : a systematic literature review and meta - analysis. Clin Rheumatol 40:4829-4836. https://doi.org/10.1007/s10067-021-05783-8

2. Bosco L, Peroni A, Schena D, Colato C, Girolomoni G (2011) Cutaneous manifestations of Churg-Strauss syndrome: report of two cases and review of the literature. Clin Rheumatol 30:573580. https://doi.org/10.1007/s10067-010-1593-1

3. Delplace D, Da Costa LM, Goffin L, Wechsler ME, Sass U, Andre J, Dangoisse C, Song M (2007) Oral ulceration: an unusual manifestation of Churg-Strauss Syndrome. J Eur Acad Dermatology Venereol 21:969-972. https://doi.org/10.1111/j.1468-3083.2006. 02086.x

4. Ivanoff CS, Ivanoff IK, Hottel TL (2018) Multiple oral ulcerations: a very rare case of Churg-Strauss syndrome with renal disease. J Oral Maxillofac Surg Med Pathol 30:175-179. https://doi. org/10.1016/j.ajoms.2017.11.007

5. Otsuka T, Iwata H, Kosumi H, Muramatsu K, Ito T, Tsujiwaki M, Fujita Y, Kamaguchi M, Kitagawa Y, Shimizu H (2019) Refractory oral ulcers in eosinophilic granulomatosis with polyangiitis. J Dermatol 46:e377-e378. https://doi.org/10.1111/1346-8138. 14897

Publisher's note Springer Nature remains neutral with regard to jurisdictional claims in published maps and institutional affiliations. 